\title{
Concrete-filled round-ended steel tubular stub columns under concentric and eccentric loads
}

\author{
A. Piquer ${ }^{a *}$, D. Hernández-Figueirido ${ }^{a}$ and C. Ibañez ${ }^{a}$ \\ ${ }^{a}$ Departamento de Ingeniería Mecánica y Construcción, Universitat Jaume I, Spain \\ *corresponding author, e-mail address: ana.piquer@uji.es
}

\begin{abstract}
In the past, many works to study the mechanical behaviour of concrete filled steel tubular (CFST) stub columns have been conducted. Some of the applications of these composite columns oblige to meet higher requirements of ductility and load-bearing capacity. Traditionally, circular and rectangular tubes have been employed but recently new crosssectional shapes of these composite columns are being designed and investigated with the aim of optimizing their mechanical behaviour. In this line, concrete-filled round-ended steel tubular columns (CFRT) have appeared as an alternative. However, the number of experimental programs to characterize their mechanical response is still scarce. In order to contribute to the test results database, in this paper an experimental study of 9 concretefilled round-ended steel tubular stub columns is presented. All the specimens were designed with the same cross-sectional round-ended shape and have the same dimensions. In this program, both normal and high-strength concrete were employed as infill. During the tests, the columns were subjected to axial compression loads but under different eccentricities. The influence of eccentricity and concrete strength on the ultimate load bearing capacity of the concrete-filled round-ended steel tubular are discussed. Besides, the combined action of both components in this type of concrete-filled tubes as well as the effect of the concrete infill are studied.
\end{abstract}

Keywords: Concrete-filled stub columns; round-ended; CFRT; CFST; eccentric loads.

\section{Introduction}

It is well known that concrete-filled steel tubular (CFST) columns have excellent structural characteristics like high load capacity, ductility, large energy absorption capacity in case of seismic action and excellent fire resistance. These are some of the reasons that make them an interesting and competitive option for different structures like high-rise buildings, bridges, warehouses, etc. [1]. All these advantages are mainly due to the composite action existing between the two components. The concrete core is confined by the steel tube which increases the compressive strength of the section and its ductility. Meanwhile, the infill concrete eliminates or delays inward local buckling of the steel tube.

Nowadays, the structural behaviour of CFST columns and the critical parameters affecting it have been studied with a wide number of experiments and numerical models [2]. A state of the art of the research carried out on composite columns considering experimental and analytical studies can be found in Shanmugam and Lakshmi [3]. Most of the studies are focused on columns built up with circular, square or rectangular tubes. Traditionally, these are the most studied and used cross-sectional shapes.

The different flexural rigidities about the two principal axes in rectangular CFST columns make them attractive for elements subjected to bending. But rounded shapes are also particularly attractive to designers and this fact has encouraged researchers to carry out some studies about elliptical sections. The structural behaviour of filled elliptical tubes has been investigated both analytically ([4], [5]) and experimentally ([6]-[10]). A cross-section that can offer a behaviour similar to that of the elliptical one is the round-ended section, also called oval, flat-sided oval or stadium sections. 
A round-ended section is a geometric figure consisting of a rectangle whose ends are capped off with semicircles. The flat sides of the section can be profited in the design of the structures junctions, because these sections can be joined easily to other structural elements. Fig. 1 shows the cross-section of the concrete-filled roundended steel tubular (CFRT) columns studied in this article, where $\mathrm{B}$ and $\mathrm{D}$ are the cross sectional dimensions and $t$ is the wall-thickness of the steel tube. In Fig. 2 the steel tubes used to prepare the specimens are shown.

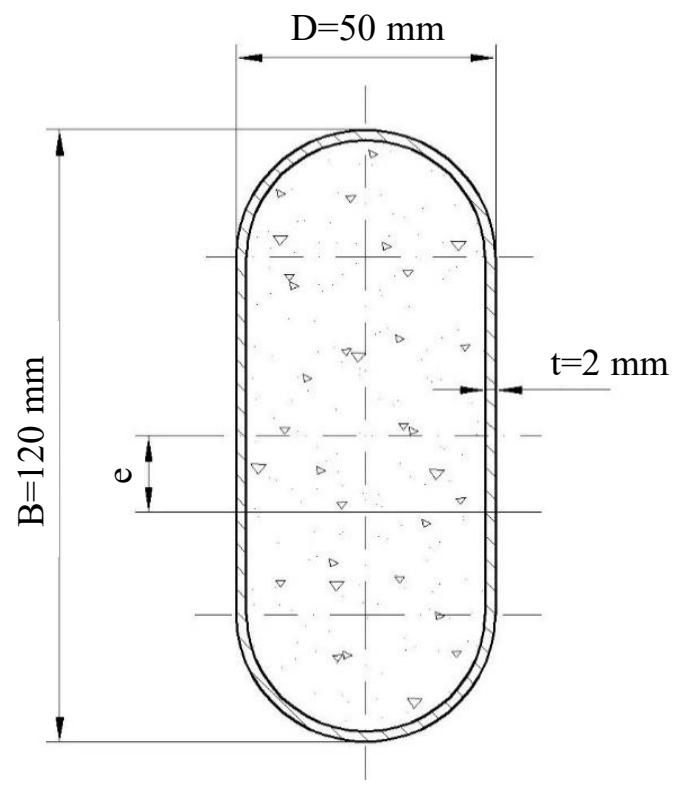

Fig. 1. CFRT column cross-section.

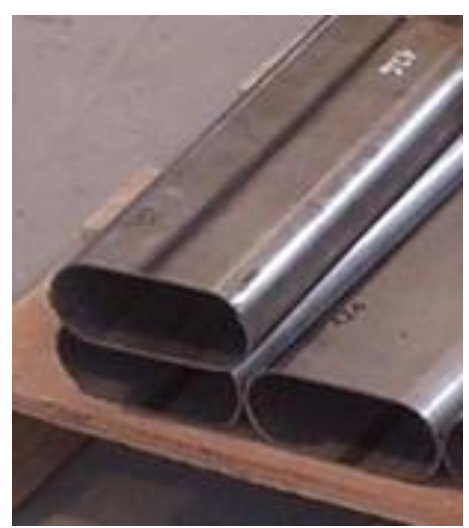

Fig. 2. Round-ended steel tubes.

Up to date, the bibliography offers very few studies about hollow round-ended steel columns [11]. Only an experimental study of 22 CFRT stub columns under axial compression together with a finite element model is presented in Faxing et al. [12]. However, no experiments have been found with CFRT stubs columns under axial compression with eccentricity.
Related to the application of the corresponding codes, few studies have been found on hollow tubes with this cross-sectional shape. Nevertheless, the work carried out by Zhu and Young [11] on hollow round-ended sections under axial compression revealed that when the EC3 design rules are applied to these hollow columns the predictions are quite conservative.

Thus, this paper presents the analysis of the results obtained from a series of tests on 9 CFRT stub columns with the same cross-sectional shape and dimensions. Two different types of concrete were employed in this program as infill: normal and high-strength concrete. During the tests, the columns were subjected to axial compression loads but under different eccentricities. The influence of eccentricity and concrete strength on the ultimate load bearing capacity of the concrete-filled round-ended steel tubular are discussed.

\section{Experimental program}

\subsection{Columns analysed and test procedure}

In this work, a total of 9 stub columns ( $\mathrm{L}=$ $300 \mathrm{~mm}$ ) were tested with the objective of evaluating the effect of the eccentricity and the concrete infill on the load-bearing capacity. All the columns have the same dimensions. Three of them were filled with normal strength concrete (NSC) with a nominal concrete strength of 30 $\mathrm{MPa}$ and the other 6 were filled with highstrength concrete (HSC), with a nominal concrete strength of $90 \mathrm{MPa}$. In the design of this research program, the focus was put on the effect of HSC in this section, but including tests on some of the columns filled with NSC to establish a proper comparison. Table 1 shows the details of the materials of each specimen, the load eccentricity and the experimental bearing capacity of each column.

The concrete infill was prepared in a planetary mixer and cured during 28 days until the day when the test was performed. In order to evaluate the compressive strength, 150x300 mm cylinders were fabricated and cured under the same conditions as the specimens. All the columns were manufactured and tested at the Universitat Jaume I in Castellón (Spain) in a horizontal testing frame with capacity of 5000 $\mathrm{kN}$.

The notation adopted to identify the tests specimens was: ov.fc_e (i.e. ov.90_10), where 
ov is the shape, $\mathrm{fc}$ is the nominal concrete strength in $\mathrm{MPa}$ and $\mathrm{e}$ is the load eccentricity in $\mathrm{mm}$.

In the study, the load was applied on five different eccentric positions: 5, 10, 20, 25 and 50 $\mathrm{mm}$. Additionally, a concentrically loaded case was performed always as reference $(\mathrm{e}=0 \mathrm{~mm})$. Eccentricity was applied over the strong axis of symmetry of the cross-section and with the same value at both ends. All the columns were tested under pinned-pinned (P-P) boundary conditions.

In this campaign, all the specimens were obtained from the same cold formed steel hollow tube of nominal strength S275. The actual yield strength of the tubes was determined by the corresponding coupon tests giving a value of $306.98 \mathrm{MPa}$. For the analysis, the modulus of elasticity of steel was set to $210 \mathrm{GPa}$ according to the European standards.

Table 1. Specimen details.

\begin{tabular}{lccccc}
\hline Name & $\begin{array}{c}\mathrm{f}_{\mathrm{c}} \\
(\mathrm{MPa})\end{array}$ & $\begin{array}{c}\mathrm{e} \\
(\mathrm{mm})\end{array}$ & $\begin{array}{c}\mathrm{N}_{\exp } \\
(\mathrm{kN})\end{array}$ & SI & CCR \\
\hline ov.30_00 & 40.80 & 0 & 384.7 & 1.02 & 2.15 \\
ov.30_20 & 40.80 & 20 & 286.3 & 0.76 & 1.61 \\
ov.30_50 & 40.80 & 50 & 269.5 & 0.71 & 1.53 \\
& & & & & \\
ov.90_00 & 89.36 & 0 & 577.3 & 0.94 & 3.23 \\
ov.90_05 & 89.36 & 5 & 566.3 & 0.92 & 3.18 \\
ov.90_10 & 89.36 & 10 & 522.7 & 0.85 & 2.94 \\
ov.90_20 & 89.36 & 20 & 427.3 & 0.69 & 2.41 \\
ov.90_25 & 89.36 & 25 & 381.0 & 0.62 & 2.15 \\
ov.90_50 & 89.36 & 50 & 369.7 & 0.60 & 2.10 \\
\hline
\end{tabular}

\section{Results}

\subsection{Maximum load}

The value of the experimental ultimate load $\left(\mathrm{N}_{\exp }\right)$ was registered in each test and is summarized in Table 1. Also Fig. 3 shows the ultimate load reached by each specimen versus the eccentricity. Two series can be distinguished, one for those columns filled with NSC (C30) and another for those with HSC (C90).

It can be observed in Fig. 3 that the ultimate load decreases when the load eccentricity is higher. The influence of the eccentricity is greater for eccentricities values less than $25 \mathrm{~mm}$, which represents around the $40 \%$ of the sectional width of the column. For loads applied with an eccentricity lower than $25 \mathrm{~mm}$, the ultimate load significantly decreases with an increment in the eccentricity. Nevertheless, for greater eccentricities, the value of the ultimate load decreases slightly with eccentricity.

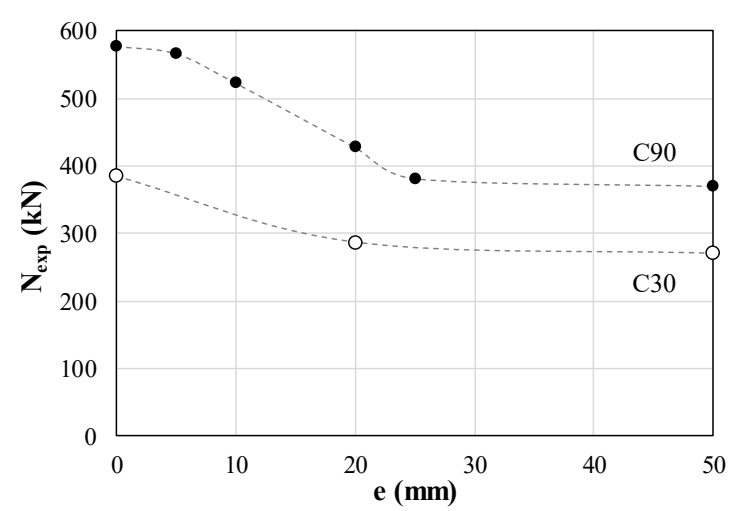

Fig. 3. Experimental ultimate load vs eccentricity.

For both concrete strengths, NSC and HSC, the ultimate load decreases around $25 \%$ when the load is applied with an eccentricity of $20 \mathrm{~mm}$. The influence of the eccentricity is rather higher for columns built with HSC than those built with NSC.

It could be thought that the change in the maximum load is due to the different behaviour of the rounded parts. It is well known that the confinement of the concrete core in circular steel tubes gives to the columns a better behaviour under higher loads. Nevertheless, the rounded parts are half circle, and even if the load was applied in the centre of the rounded part of the section, the value of the eccentricity would be 35 $\mathrm{mm}$.

However, in the graph shown in Fig. 3, a change in the slope occurs around $\mathrm{e}=25 \mathrm{~mm}$. This point is still within the plane region of the steel tube. From that point on, a different behaviour is noticed but the change does not correspond with the geometrical change.

\subsection{Strength Index}

A strength index is defined to quantify the effect of the composite action in the crosssectional capacity. The Strength Index (SI), calculated as the ratio between the theoretical cross-sectional capacity and the actual ultimate load, has been obtained for each column by means of Eq. (1).

$$
S I=\frac{\mathrm{N}_{\mathrm{exp}}}{\mathrm{A}_{\mathrm{s}} \mathrm{f}_{\mathrm{y}}+\mathrm{A}_{\mathrm{c}} \mathrm{f}_{\mathrm{c}}}
$$

where $\mathrm{N}_{\exp }$ is the experimental ultimate load, $\mathrm{A}_{\mathrm{s}}$ is the cross-sectional area of the steel tube, $f_{\mathrm{y}}$ is the yield strength of the steel, $\mathrm{A}_{\mathrm{c}}$ is the cross- 
sectional concrete area and $f_{c}$ the cylindrical concrete strength.

The SI calculated for each specimen is plotted in Fig. 4 in function of the eccentricity. It can be observed that generally, the SI decreases with the increase of the eccentricity for both NSC and HSC tubes. The figure shows how columns built with NSC present experimental results very similar to the theoretical cross-sectional capacities of the specimens with concentric load and that SI decreases for greater values of eccentricity. However, in the case of HSC, even the value of SI for axially loaded columns is lower than the unit, which means that the sectional capacity calculated as the sum of all the components overestimates the ultimate load of the composite section.

The SI diminishes significantly up to eccentricity values of $25 \mathrm{~mm}$. For larger eccentricities the SI value decreases very slightly.

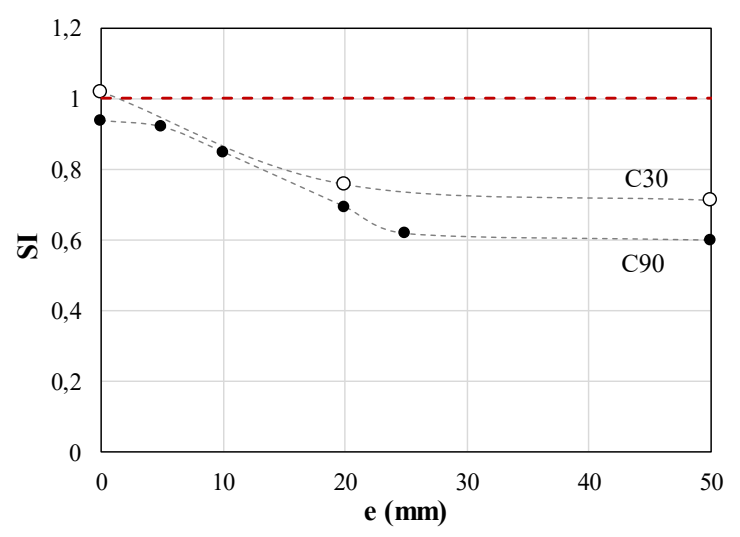

Fig. 4. Variation of SI with eccentricity.

\subsection{Concrete Contribution Ratio}

In a similar way, the contribution of the concrete infill was analysed for each specimen by means of the Concrete Contribution Ratio (CCR) which can be calculated by Eq. (2).

$$
\mathrm{CCR}=\frac{\mathrm{N}_{\text {exp }}}{\mathrm{N}_{\text {hollow,EC3 }}}
$$

where $\mathrm{N}_{\exp }$ is the experimental ultimate load and $\mathrm{N}_{\text {hollow,EC3 }}$ is the theoretical capacity of the steel hollow tube according to the Eurocode 3 (EC3) [13]. The value of the theoretical capacity of the steel hollow tube is calculated for each column by Eq. (3).

$$
\mathrm{N}_{\text {hollow,EC3 }}=\frac{\mathrm{f}_{\mathrm{y}}}{\frac{1}{\mathrm{~A}_{\mathrm{s}}}+\frac{\mathrm{e}}{\mathrm{W}_{\mathrm{el}}}}
$$

where $A_{s}$ is the cross-sectional area of the steel tube, $\mathrm{f}_{\mathrm{y}}$ is the yield strength of the steel, $\mathrm{e}$ is the eccentricity and $\mathrm{W}_{\mathrm{el}}$ is the elastic section modulus.

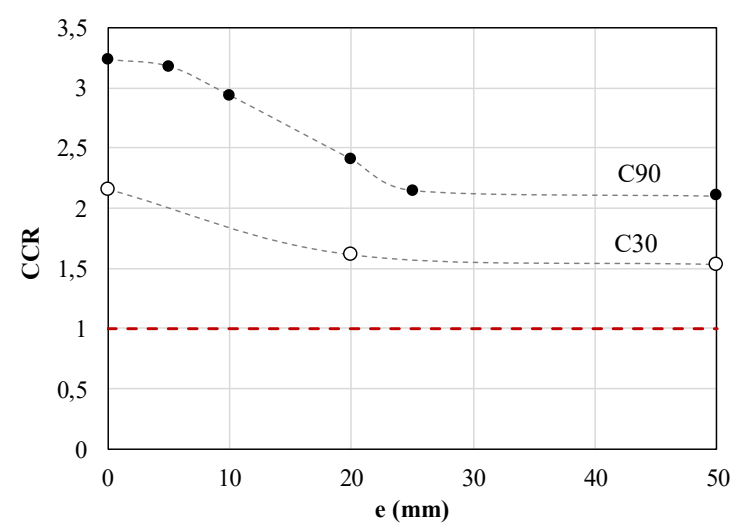

Fig. 5. Variation of CCR with eccentricity.

In Fig. 5, the variation of the CCR with the eccentricity applied to the columns is shown. The results obtained corroborate the trend observed for the ultimate load. The effect of the concrete infill is more important in those columns with HSC, even when the eccentricity increases. When the axial load is applied without eccentricity the contribution of the concrete is more than three times the contribution of the steel if the specimen is built with HSC, and more than twice if it is built with NSC. When the values of eccentricity rise, the values of CCR decrease. When the eccentricity is higher than 25 $\mathrm{mm}$ the slope of CCR values becomes smoother. That is to say, for higher eccentricity values, the steel contribution is significantly higher.

\section{Conclusions}

In this work, the experimental results of 9 tests on concrete-filled round-ended steel tubular stub columns subjected to eccentric loads have been presented. The columns were filled with two different concretes: NSC and HSC, and the loads were applied with eccentricity on the strong axis. The maximum loads reached by the columns have been presented. It can be noticed that highest loads are supported by columns filled with HSC. The eccentricities affect the capacity of the columns, especially with eccentricities between 5 and $25 \mathrm{~mm}$. With higher eccentricities, the loads decrease very slightly. This can be due to the benefits given by the confinement of the circular part of the CFRT section. 
The results of the SI analysis show that those columns filled with NSC and load concentrically offer experimental results very close to the theoretical ones. On the other hand, those filled with HSC show a SI lower than one. In both cases, columns built with HSC reduce their SI when the eccentricity increases and SI decreases considerably while the eccentricity in the major axis rises until $25 \mathrm{~mm}$. Finally, the analysis of the CCR corroborates the same trend observed for the values of the ultimate load.

\section{Acknowledgements}

The authors would like to express their sincere gratitude to Universitat Jaume I and the project P1-1A2015-06 entitled "Análisis experimental de pilares mixtos src. Nuevos modelos de cálculo empleando técnicas de inteligencia artificial" and the BEST/2017/147 granted by Conselleria d'Educació, Investigació, Cultura i Esport, GVA.

\section{References}

[1] Zhao XL, Han LH, Lu H. Concrete-filled tubular members, 1st Ed. Oxon: Spon Press; 2010.

[2] Goode D. Composite columns - 1819 tests on concrete-filled steel tube columns compared with Eurocode 4. The Structural Engineer 2008; 86 (16): 33-38.

[3] Shanmugam NE, Lakshmi, B. State of the art report on steel-concrete composite columns. Journal of Constructional Steel Research 2001; 57(10): 1041-1080.

[4] Bradford MA, Roufegarinejad A. Elastic local buckling of thin-walled elliptical tubes containing elastic infill material. Interaction and Multiscale Mechanics 2007; 1(1): 143-156.

[5] Dai X, Lam D. Numerical modelling of axial compressive behaviour of short concrete-filled elliptical steel columns. Journal of Constructional Steel Research 2010; 66 (7): 931942.

[6] Jamaluddin N, Lam D, Dai XH, Ye J. An experimental study on elliptical concrete filled columns under axial compression. Journal of Constructional Steel Research 2013; 87: 6-16.

[7] Ren QX, Han LH, Lam D, Li W. Tests on elliptical concrete filled steel tubular (CFST) beams and columns. Journal of Constructional Steel Research 2014; 99: 149-160.

[8] Uenaka K. Experimental study on concrete filled elliptical/oval steel tubular stub columns under compression. Thin-Walled Structures 2014; 78: 131-137.
[9] Chan TM, Gardner L, Law KH. Structural design of elliptical hollow sections: a review. Structures and Buildings 2010; 163(6): 391-402.

[10] Sheehan T, Dai XH, Chan T-M, Lam D. Structural response of concrete-filled elliptical steel hollow sections under eccentric compression. Engineering Structures 2012; 45: 314-323.

[11]Zhu J-H, Young B. Design of cold-formed steel oval hollow section columns. Journal of Constructional Steel Research 2011; 67: 437452.

[12]Faxing D, Lei F, Zhiwu Y, Gang L. Mechanical performances of concrete-filled steel tubular stub columns with round ends under axial loading. Thin-Walled Structures 2015; 97: 22-34.

[13]EN 1993-1-1. Eurocode 3. Design of steel structures. Part 1-1: General rules and rules for buildings. Brussels (Belgium): Comité Européen de Normalisation (CEN); 2005. 